\title{
ФАКТОРЫ ПРОФЕССИОНАЛЬНОЙ НАДЕЖНОСТИ СИНХРОННОГО ПЕРЕВОДЧИКА
}

\section{FACTORS OF PROFESSIONAL RELIABILITY OF A SIMULTANEOUS INTERPRETER \\ D. Balaganov}

Summary: This article is dedicated to the issues related to the professional reliability of a simultaneous interpreter. It provides the understanding of the professional reliability both in general sense and in relation to the simultaneous interpretation. The author, from the point of view of the cognitive dynamic concept, views interpretation-related and psychoemotional factors. He comes to the conclusion that these are the groups of factors that affect an interpreter in the process of the simultaneous interpretation most. In conclusion, the author underlines the remaining topicality of the professional reliability-specific research.

Keywords: simultaneous interpretation, cognitive dynamic concept, professional reliability, interpretation-related factors, psychoemotional factors, stressful activity.

\section{BBEAEHИE}

$\mathrm{C}$ инхронный перевод, будучи стрессогенным процессом, накладывает на переводчика определенные требования, которые тому необходимо выполнять для того, чтобы быть в состоянии успешно справиться с синхронно-переводческой задачей. Исследования таких требований всегда отличались определенной актуальностью, поскольку они изучают причинно-следственную связь всех процессов, обеспечивающих деятельность синхронного переводчика.

Нами ранее уже отмечалось [3], что переводчиксинхронист в процессе своей профессиональной деятельности сталкивается с различными негативными стрессогенными факторами, как объективными, так и субъективными. В настоящей статье остановимся на совокупности таких факторов, которые определяют понятие профессиональной надежности синхронного переводчика с позиций когнитивно-динамической концепции. В этой заключается новизна нашего исследования.

Цель настоящего исследования - изучить понятие «профессиональная надежность» как в общем понимании, так и в преломлении к синхронному переводу. Для этого мы выполнили ряд задач, а именно:

- ввести понятие «профессиональная надежность синхронного переводчика»;

\author{
Балаганов Дмитрий Владимирович \\ К.филол.н., Военный университет Министерства \\ обороны Российской Федерации, \\ dmitryrus@yandex.ru
}

Аннотация: Настоящая статья посвящена вопросам профессиональной надежности синхронного переводчика. В ней дается понимание профессиональной надежности как в общем смысле, так и применительно к ситуации синхронного перевода. Автор с позиций когнитивно-динамической концепции рассматривает переводческие и психоэмоциональные факторы профессиональной надежности. Он приходит к выводу о том, что именно эти группы факторов оказывают наибольшее влияние на переводчика в процессе синхронного перевода. В заключение автор отмечает непреходящую актуальность исследований вопросов профессиональной надежности.

Ключевые слова: синхронный перевод, когнитивно-динамическая концепция, профессиональная надежность, переводческие факторы, психоэмоциональные факторы, стрессогенная деятельность.

- выявить факторы профессиональной надежности синхронного переводчика;

- рассмотреть переводческие и психоэмоциональные факторы профессиональной надежности, присущие когнитивно-динамической концепции.

Результаты нашего исследования могут быть использованы для дальнейшего изучения теоретических и прагматических аспектов синхронного перевода, а также при подготовке синхронно-переводческих кадров в интересах различных государственных структур.

\section{О ПРОФЕССИОНА^ЬНОЙ НААЕУКНОСТИ}

Понятие «профессиональная надежность» присуще практически всем сферам деятельности человека [7, 9, 10]. В общем смысле она характеризует безотказность, безошибочность и своевременность действий индивида для достижения конкретной цели в заданных условиях при взаимодействии с технической системой, другими специалистами [4]. Функциональная надёжность - это свойство функциональных систем человека обеспечивать его динамическую устойчивость в выполнении профессиональной задачи в течение определённого времени и с заданным качеством. Она отражает характер энергетического и информационного приспособления человека к процессу. Надёжность неразрывно связана с работоспособностью как системным свойством, образующимся в результате включения в деятельность [8]. Про- 
фессиональная надёжность характеризует человека по конечному результату деятельности, по точности и своевременности действий в трудовом процессе. Функциональная надёжность отражает устойчивость и адекватность реактивности организма в конкретных условиях деятельности [6].

Применительно к синхронно-переводческой деятельности профессиональная надежность переводчика заключается в способности своевременно принимать адекватные переводческие решения, а также оперативно реагировать на быстро меняющиеся условия ситуации перевода, сохраняя, при этом, неизмененное состояние своего языкового сознания [1].

Согласно подходу Национального органа по аккредитации устных и письменных переводчиков (NAATI) Австралии, к примеру, переводчики должны обладать определенным набором знаний, навыков и качеств. В их документе [13] выделяются группы компетенций, которыми должен владеть любой переводчик. К числу таких компетенций относятся: языковая, межкультурная, исследовательская, технологическая, тематическая, этическая, переключения между различными задачами, предоставления переводческих услуг. Каждая компетенция имеет свой собственный набор навыков и знаний. При этом качества переводчика не меняются. Он должен быть внимателен к деталям, надежным, объективным, уважительным, уверенным в себе, стремиться к наилучшему результату, к обучению, к сотрудничеству, к решению возникающих проблем, обладать самоанализом.

На наш взгляд, все эти компетенции можно разделить на три группы: переводческие, социокультурные и технологические. Однако ни одна из них не включает психоэмоциональную составляющую, которая является краеугольным элементом когнитивной системы синхронного перевода. Такие качества, как уверенность в себе, решение проблем и самоанализ, в некоторой степени затрагивают психоэмоциональную сферу. Но и они не в полной мере отвечают потребностям исследовать то, как переводчик реагирует на стрессогенные факторы, какие решения принимает для преодоления их негативного влияния.

С точки зрения когнитивно-динамической концепции, синхронный перевод представляет собой когнитивную систему, состоящую из когнитивных механизмов, которые обеспечивают реализацию всей синхронно-переводческой задачи [2]. На функционирование этих когнитивных механизмов оказывают влияние объективные и субъективные факторы. При этом изменяется состояние языкового сознания переводчика, который, в свою очередь, предпринимает шаги по адаптации к новым условиям ситуации перевода или по восстановлению неизмененного состояния языкового сознания.
В связи с вышеизложенным, мы предприняли попытку рассмотреть с позиций когнитивно-динамической концепции те факторы, которые оказывают непосредственное влияние на деятельность переводчика-синхрониста. К ним мы относим переводческие и психоэмоциональные факторы. Все остальные аспекты играют, на наш взгляд, второстепенную роль в процессе синхронного перевода.

\section{ПЕРЕВОАЧЕСКИЕ ФАКТОРЫ}

На наш взгляд, к числу переводческих факторов профессиональной надежности переводчика-синхрониста относятся знание двух языков, владение переводческими приемами и стратегиями [5] и тематикой мероприятия с учетом культурных особенностей аудитории.

Знание двух языков подразумевает владение лексическим, грамматическим составами иностранных языков, их фразеологией. Переводчик также должен следить за тенденциями в развитии двух языков. В зависимости от конкретной языковой пары системы языков могут в большей или меньшей степени быть схожими (например, языковая пара русский-украинский в сравнении с парой русский-английский или русский-китайский). На наш взгляд, чем ближе языковые картины мира, тем более схожи соответствующие языковые пары.

Помимо собственно знания языков, переводчик должен владеть и тематической составляющей конкретного мероприятия. Сюда мы относим как специальную лексику, которая обычно используется на мероприятиях по такой тематике, так и возможные аббревиатуры, которые могут встретиться в выступлениях ораторов. Например, на заседании стран-членов АСЕАН и их партнеров нередко можно услышать такие аббревиатуры, как IPC (initial planning conference - начальная планирующая конференция, НПК), FPC (final planning conference - заключительная планирующая конференция, ЗПК), СоС (code of conduct - кодекс поведения в Южно-Китайском море, КП в ЮКМ), ADMM Plus (ASEAN Plus defense ministers meeting - заседание министров обороны странчленов АСЕАН и диалоговых партнеров, СМОА Плюс) и другие.

Самый главный, по нашему мнению, переводческий фактор профессиональной надежности синхронного переводчика - это владение переводческими приемами и стратегиями. Они помогают поддерживать гибкость всей когнитивной системы синхронного перевода, обеспечивая бесперебойное функционирование когнитивных механизмов. Есть определенный набор подходов, которые используются переводчиком в тех или иных ситуациях. К примеру, если произношение оратора отличается от языковой нормы (влияние на когнитивный механизм восприятия и понимания), то зачастую пере- 
водчику приходится принимать решение на основе нескольких услышанных фонем и собственных фоновых знаний. Преодоление трудностей на данном этапе напрямую связано с функционированием когнитивного механизма обработки информации, который помимо прочего отвечает за распознавание интенции оратора и декодирование исходного сообщения. Отметим, что перенос значения от одного языка к другому происходит именно при помощи образа исходного сообщения.

Важную роль играет направление перевода (влияние на когнитивные механизмы переключения между языками и выбора варианта перевода). Например, при переводе с русского языка на английский важно помнить об актуальном членении русского высказывания и о порядке слов английского предложения. Часто переводчику необходимо делать второстепенные члены русского предложения главными членами английского предложения (В результате таких незаконных действий девальвируется международное право, на котором зиждется послевоенное мироустройство - As a result, such illegal actions devalue the international law that is the basis of the post-war world order ${ }^{1}$ ).

Отдельно отметим роль речевой компрессии, которая позволяет экономить когнитивные усилия переводчика, прибегая к стратегии опущения избыточной информации (оказывать помощь = помогать, чинить препятствия = мешать, have been training = to train).

Для поддержания функционирования когнитивных механизмов вероятностного прогнозирования и синхронизации задействуется совокупность всех переводческих факторов. В частности, знание лексико-грамматической структуры двух языков, а также тематики мероприятия обеспечивает работу вероятностного прогнозирования. В свою очередь бесперебойное функционирование других когнитивных механизмов помогает работе механизма синхронизации, который отвечает за распределение внимания. Внимание переводчика-синхрониста отличается определенной гибкостью и смещается в сторону когнитивного механизма, в работе которого возникли трудности. При этом функционирование других когнитивных механизмов продолжает контролироваться когнитивным механизмом синхронизации.

\section{ПСИХОЭМОШИОНААЬНЫЕ ФАКТОРЫ}

Психоэмоциональные факторы профессиональной надежности охватывают психологическую готовность к работе в стрессогенных меняющихся условиях ситуации перевода, оперативное реагирование на возника- ющие трудности.

При подготовке к акту синхронного перевода, помимо собственно языковых вопросов, переводчик старается настроить свою нервную систему на работу в условиях стресса. За стрессоустойчивость нервной системы человека отвечают определенные биоритмы головного мозга. Их настройка возможна как аппаратными, так и неаппаратными средствами. К числу аппаратных средств относятся специальные приборы, помогающие индуцировать необходимые биоритмы и сохранить их работу в автономном режиме. Неаппаратными средствами мы называем любые средства, способствующие требуемой калибровке психики переводчика к стрессогенной деятельности. Их роль могут выполнять прослушивание музыки, рассматривание картин или другой визуализации. Также важно отметить и степень удовлетворенности физиологических потребностей (сон, пища, приятное общение), которая оказывает существенное влияние на психоэмоциональную сферу переводчика-синхрониста.

Будучи психологически готовым к синхронному переводу как стрессогенной деятельности, переводчик постоянно испытывает влияние различных факторов, которые могут иметь негативные последствия для выполнения переводческой задачи. К числу таких факторов, например, можно отнести техническую исправность аппаратуры, кондиционирование воздуха и температуру в кабине синхронного перевода.

Однако самый важный фактор, оказывающий максимальное влияние на переводчика, - это оратор. Являясь автором исходного сообщения, он стимулирует и направляет все речемыслительную деятельность переводчика-синхрониста. От того, насколько понятна его речь и основной посыл, будет зависеть, насколько точно сможет переводчик передать его на языке перевода. В этой связи одним из самых стрессогенных факторов, на наш взгляд, является непонимание оратора. При возникновении такой трудности переводчик задействует значительные когнитивные ресурсы и внимание на ее преодоление, что может негативно сказаться на функционировании других когнитивных механизмов. Здесь необходимо отметить важную роль напарника, который в такой момент способен помочь с проблемой понимания и не допустить изменения состояния языкового сознания работающего на микрофоне переводчика. Вообще, то, как воспринимает стресс сам переводчик, определяет степень стрессогенности любого фактора влияния.

1 Перевод автора. 


\section{ВыВO $\triangle$ Ы}

В результате проведенного нами исследования мы пришли к следующим выводам:

1. Профессиональная надежность синхронного переводчика - это способность принимать адекватные переводческие решения и оперативно реагировать на возникающие в процессе перевода трудности, сохраняя при этом неизмененное состояние языкового сознания.

2. К числу факторов профессиональной надежности синхронного переводчика относятся: переводческие, психоэмоциональные и социокультурные. Кроме того, переводчик-синхронист должен уметь работать с соответствующей аппаратурой синхронного перевода, обладать коммуникативными навыками и соблюдать этические нормы.

3. Сточки зрения когнитивно-динамической концепции, переводческие факторы профессиональной надежности охватывают знание пары языков, владение необходимой терминологией конкретного мероприятия, а также способность применять те или иные переводческие приемы и стратегии, направленные на обеспечение функционирования когнитивных механизмов синхронного перевода.

4. Психоэмоциональные факторы включают в себя психологическую готовность к стрессогенной деятельности, а также оперативное реагирование на возникающие трудности в процессе синхронного перевода.

\section{ЗАКАЮЧЕНИЕ}

В настоящей статье мы рассмотрели переводческие и психоэмоциональные факторы профессиональной надежности синхронного переводчика. Несмотря на то, что число этих факторов больше, именно эти две группы, с точки зрения когнитивно-динамической концепции, являются основными для обеспечения функционирования когнитивных механизмов синхронного перевода.

Учитывая тот факт, что синхронно-переводческое сообщество уже выработало те или иные критерии оценки деятельности переводчика-синхрониста [11, 12, 14], отмечаем важность учета индивидуальных особенностей обучающихся и практикующих переводчиков. Другими словами, не существует универсальных критериев, выполняя которые переводчик будет выдавать адекватный перевод.

Случилось так, что, к примеру, в Вооруженных силах отсутствует система подготовки синхронно-переводческих кадров, а потребность в них непрерывно растет. Поэтому опытные последовательные переводчики обучают себя сами или прибегают к помощи более опытных коллег. Такой процесс прошли, и мы сами. Несмотря на изобилие предлагаемых услуг по подготовке специалистов в области синхронного перевода, их качество не всегда соответствует ожиданиям. Поэтому продолжение исследований в этой области не утратит своей актуальности и в будущем.

1. Балаганов Д.В. Динамика состояния языкового сознания индивида в процессе синхронного перевода // Вестник Московского государственного областного университета. Серия: Лингвистика. №1. М.: МГОУ, 2020. С.6-14.

2. Балаганов Д.В., Давыдова Т.Ю. Когнитивные механизмы в синхронном переводе // Вестник Нижегородского государственного лингвистического университета им. Н.А. Добролюбова. №47. Нижний Новгород: ННглУ, 2019. С.19-32.

3. Балаганов Д.В., Князева Е.Г. Психолингвистические основы синхронного перевода // Филологические науки. Вопросы теории и практики. Т.13. №3. Тамбов: Грамота, 2020. С.192-197.

4. Бодров В.А., Орлов В.Я. Психология и надежность: человек в системах управления техникой. - М.: Институт психологии РАН, 1998. - 288 с.

5. Илюхин В.М. Стратегии в синхронном переводе (на материале англо-русской и русско-английской комбинаций перевода): дис. на соиск. учен. степ. к.филол.н. 10.02.20. - М., 2001. 206 с.

6. Крук В.М. Психология надежности специалиста: история и современность // Вестник Московского государственного областного университета. Серия: Психологические науки. М.: МГОУ, 2010. С.181-188.

7. Марищук Л.В., Яценко И.В. Развитие профессионально значимых качеств курсантов, обеспечивающих профессиональную надежность офицеров // Наука-Образование-Профессия: системный личностно-развивающий подход. Под ред. Л.М. Митиной. М.: «Перо», 2019. С.354-357.

8. Осадчук 0.Л. Формирование профессиональной надежности специалиста // Фундаментальные исследования. Пенза: «Академия Естествознания», 2005. C.86-88.

9. Пугачева Е.В. Психологические детерминанты профессиональной надежности сотрудника учреждения высшего профессионального образования // Специальная психология. №2, 2013. С.5-7.

10. Чекунов А.А. Понятие профессиональной надежности субъекта на этапе профессионального становления в вузе // Проблемы психолого-педагогической работы в современном образовательном учреждении: сборник материалов II международной научно-практической конференции. СПб: 000 «Ниц Арт», 2017. C.145-148. 
11. Gile, D. (2018). Simultaneous Interpreting // CHAN, Sin-wai (ed). An Encyclopedia of Practical Translation and Interpreting. Hong Kong: The Chinese University Press, P.531-561.

12. Kalina, S. (2012). Quality in interpreting // Handbook of translation studies, Vol.3. P.134-140.

13. NAATI Interpreter Certification: Knowledge, Skills and Attributes [Электронный ресурc]. URL: https://www.naati.com.au/wp-content/uploads/2020/01/ nterpreter-KSA-Paper.pdf (дата обращения: 05.05.2020).

14. Robinson, D. (2007). Becoming a Translator: An Introduction to the Theory and Practice of Translation. Second edition. Routledge, London, New York. 301 p.

(с Балаганов Дмитрий Владимирович (dmitryrus@yandex.ru).

Журнал «Современная наука: актуальные проблемы теории и практики»

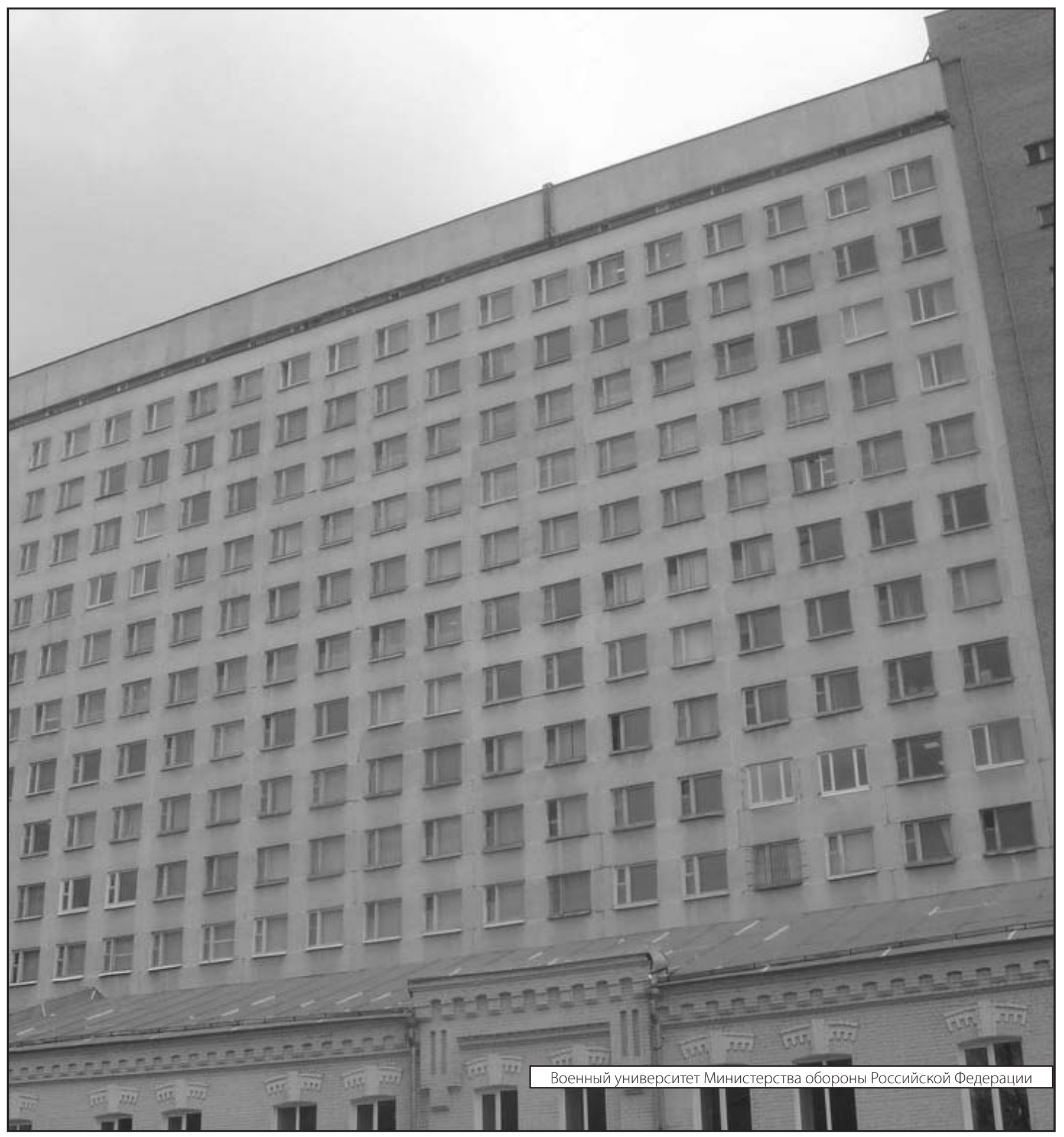

